\section{Cuban science democratic and not tied to profit}

SIR - We question the comparison made in your News Feature "¿Vive la revolución?" (Nature 436, 322-324; 2005) between Cuban government-funded science and a corporate research programme using a top-down approach that focuses on applied science at the expense of basic research.

Reality contradicts the common view that science is undemocratic in $\mathrm{Cuba}$ - and that it is democratic in the United States.

In our experience as collaborators with Cuban scientists, science issues are first raised in local communities, then discussed at local research institutes and universities, then passed to higher levels of national ministries and the Congress, and there winnowed and prioritized. This is an up-anddown system that offers individual citizens a high level of engagement with decisionmaking processes for scientific research.

Neither have we found basic research to be neglected. For instance, there is work in underwater archaeology, palaeontology, plant and animal geography and many other topics. Indeed, Cuba probably has a better record in funding basic research than most other Latin American countries.

Both publicly and privately funded research in the United States and Europe, on the other hand, is often determined by corporate or political interests. Much research in the public interest withers for lack of resources, in favour of projects that will lead to patents and profits. Increasingly in the United States, the results of scientific research are also distorted or ignored by federal policy-makers if the science is inconsistent with the prevailing political agenda.

We should be more thoughtful about the Cuban system and our own.

Catherine Badgley*, Ivette Perfecto†

*Museum of Paleontology, University of Michigan,

†School of Natural Resources and Environment, University of Michigan,

Ann Arbor, Michigan 48109, USA

Other signatories of this letter

John Vendermeer Department of Ecology and Evolutionary Biologx University of Michigan

Gerald Smith Museum of Zoologx, University of Michigan

Richard Levins Harvard School of Public Health

\section{Bioweapons could kill more in one strike than guns}

SIR — David Whitlock, in Correspondence

( ${ }^{\circ}$ Bioterror killed five in US; guns kill 30,000 a year" Nature 436,$460 ; 2005$ ), is right about the number of people killed each year by firearms in the United States. But in fact suicide accounts for more than half of these deaths. The annual rate of firearm murder and non-negligent homicide is less than 10,000 , and is overwhelmingly more often due to handguns than to military-style firearms (Federal Bureau of Investigation Crime in the United States: Uniform Crime Report 2003, Washington DC; 2004).

The firearm is designed for use against individual targets and is incapable of having the same large-scale effect as a well-dispersed biological agent. Almost 3,000 people perished in the $9 / 11$ attacks, but a systematic biological release could conceivably claim 30,000 lives or more. We did not realistically anticipate commercial airliners being used as massively destructive devices, and are now in the difficult position of trying to determine how other major attacks could reasonably be prevented.

The firearm should not be considered in the same context as the potential nuclear, biological or chemical threat.

Michael C. Wendl

Washington University MedicalSchool, 4444 Forest Park Boulevard, Box 8501, St Louis, Missouri 63108, USA.

\section{EURYI scheme aims to stop women disappearing}

SIR — Darach Watson and colleagues, in Correspondence ( ${ }^{\circ}$ Mysterious disappearance of female investigators" Nature 436, 174; 2005), have pointed out that there were only three women among the 25 recipients of the first year's European Young Investigator (EURYI) awards.

The first year of the EURYI award scheme has been externally evaluated, in a process that included sending questionnaires to 671 applicants, with a $70 \%$ response rate, and to all participating organizations ( $100 \%$ response). We also interviewed 20 people involved in the selection. Although these data could not be released while the evaluation was under way, the report is now publidy available at www.esf.org/euryi. Raw data may be made available on request.

As a result of the recommendations emerging from the evaluation, the European Science Foundation and organizations participating in EURYI have made a number of improvements to the second year's processes, including ensuring that equal opportunities (EO) are provided to all applicants. Specific improvements include introducing at European-level selection an EO statement in refereeing/assessment documents and specific briefing on EO issues at the beginning of all peer-review meetings, such as interviews.

This approach is supported by results from the second year's EURYI awards. Of the 672 initial applicants for the second year's awards, $24 \%$ were women; $24 \%$ (31) of the
131 submitted to European selection were women, and of the 25 final recipients of awards, five (20\%) were female.

The real issue for the European Science Foundation and EURYI participating organizations is raising the proportion of female applicants at the initial stages of this competition. To achieve this goal, we are adapting our publicity for the next call for EURYI proposals.

Neil Williams

European Science Foundation, 1 quai Lezay-Marnésia, BP 90015, 67080 Strasbourgcedex, France

\section{EURYI: present procedure risks conflicts of interest}

SIR - In their Correspondence "Mysterious disappearance of female investigators" (Nature 436, 174; 2005), D. Watson and colleagues reported evidence of gender-based bias in the evaluation of applications for the first European Young Investigator (EURYI) awards. I agree with their analysis, but there were even more serious flaws in this process.

EURYI applications were first reviewed by participating national research funding organizations. About $83 \%$ of the proposals were rejected at this stage, the rest being sent for subsequent evaluation at European level. However, the initial unsuccessful applicants typically received only a very short rejection note, with no information about peer review.

The average annual grant size of EURYI is $€ 200,000$ (US\$239,000), which, in the case of my home country, Hungary, is several times more than the funding an established, productive researcher can apply for. This creates a major conflict of interest, which probably also holds true for other participating countries such as Austria, Denmark, Belgium, Ireland, Finland and Portugal.

I think the sharp drop in the number of applications for the second EURYI call in 2004 reflects the disillusionment felt by the participants.

A better procedure would have been for applicants first to submit short preliminary proposals, all of which would have been evaluated at the European level. The best applicants could then be asked to submit detailed documents for in-depth review. This would save a lot of time and effort for applicants and reviewers.

\section{Gábor Lente}

Department of Inarganic and Analytical Chemistry, University of Debrecen, H-4010 Debrecen, POB 21, Hungary

Contributions to Correspondence may be submitted to corres@nature.com. They should be no longer than $\mathbf{5 0 0}$ words, andideally shorter. Published contributions are edited. 